\title{
nature
}

geoscience

\section{The beauty of balance}

\author{
US geoscience departments are still heavily weighted towards men, especially in the most \\ senior ranks. All scientists, male or female, should work towards a more equal distribution.
}

Even in the twenty-first century, women hold less than an equal share of the world's professorships. Sadly, but not unexpectedly, the geosciences are no exception. The Backstory in this journal illustrates the field experiences of earth scientists, and other aspects of the subject rely heavily on physics and mathematics. These are not areas where females have historically been overrepresented.

Yet as noted in the Feature on page 79 of this issue, women obtained a very respectable $45 \%$ of US masters degrees in the geosciences (in 2004). In view of this number, it seems unlikely that seasickness, vertigo or a passion for high heels are keeping them from progressing to professorial levels. And of course, even in areas of science such as social sciences or psychology, where women overwhelmingly outnumber men in the student population, the majority of professors are male, and the drop in the percentage of women from first-year students to full professors is just much steeper.

The findings reported in the Feature indicate that opinions on why so few women hold full chairs in the geosciences are clearly divided along gender lines. Men who participated in the study attributed the skew mainly to historically low numbers of students, and appear happy to wait for the problem to eventually rectify itself. However, the women expressed disillusionment with the slow progress and suggest that it is the structure of academia that gets in the way - first and foremost the impossibility of combining a family with a career in research.

So opinions are divided along gender lines - the same fault line that distinguishes those who represent most of the upper echelons of academia from those who (in large numbers) dropped out somewhere between the completion of $\mathrm{PhD}$ and what would have been their first permanent position.

\section{Does men's confidence that time will bring equality just reflect their indifference?}

There is probably a strong cultural component to the perception of reasons for any differences or equalities between genders. Anecdotal evidence suggests that women in the former German Democratic Republic, where childcare facilities were widely available and the overwhelming majority of women worked, primarily viewed the abilities of men and women as equal in all aspects, and placed little emphasis on possible intrinsic differences between the genders. Meanwhile, the debate in western Germany explored whether men and women had a different outlook on life and different views and choices, trying to identify specific strengths and weaknesses of the genders. A study of US academia is therefore not necessarily globally representative. But important considerations arise from the findings, and these may well apply universally.

If the perceptions of women and men differ significantly, is there a breakdown of communication? Or does men's confidence that time will bring equality just reflect their indifference? After all, they are at best at the periphery of the problem, and at worst they stand to lose out if the proportion of women increases.

If women choose not to pursue a scientific career because science is a men's world, the atmosphere in the departments has to change. But should women also be more self-motivated or more mutually supportive? Are they taking the easy way out of a career that is precarious for everyone in the early stages, permitted to do so by a society that does not expect women to become professors?

Having a family and a career in science still appears to be mutually exclusive for a majority of women, but only for a minority of men. To address that, we need more accessible and affordable childcare facilities. But we also need fathers who spend as much time with their children as mothers do. Governments can encourage this with father-friendly policies, such as the generous provisions for paternity leave that have made a clear difference in Iceland and Denmark.

In the 1970s, the argument that a lack of young women coming up the academic ladder prevented women from having an equal share in professorships had its merits. But surely, all those female students of the 1970s, 1980s and 1990s should have been crowding into the high-profile university positions for a while now. They haven't.

To achieve a fair balance of the genders in geoscience academia, men and women must make the effort to scrutinize the motives of their decisions: for or against a female candidate for the next professorial post, for or against a career in science, and for or against an equal share (no less, no more) in the family work. 